\title{
Analisis Usability Pada Aplikasi Ayoowork Baliyoni Menggunakan Use Questionnaire
}

\author{
Putu Aryasuta Wicaksana ${ }^{1}$, Ida Bagus Alit Swamardika ${ }^{2}$, Rukmi Sari Hartati ${ }^{3}$ \\ [Submission: 27-07-2021, Accepted: 16-12-2021]
}

\begin{abstract}
Basically, building a system is to mèèt the users needs, where system must consider the ease, comfort, and satisfaction of using the information system. Several studies have shown that these aspects can be measured through Usability testing. This study analyze the Usability of a project management information system developed and used at PT. Baliyoni Saguna Group. The study has purpose to determine the level of Usability of information systems or Usability by measuring four aspects of Usability, Measurements are made using the Use Questionnaire which is measured using a Linkert scale with a scale of 5 . So it is hoped that this research in the future can be a reference for companies to continue to develop information systems to support business activities and increase company competitiveness. The results of the study indicate that the Ayoowork Baliyoni information system has a good Usability level with a score interpretation value of $62.07 \%$. The scores of each aspect measured are usefulness with a score of 593 or $62.94 \%$, ease of use $61.39 \%$, ease of learning $60.59 \%$, and satisfaction with $63.03 \%$.
\end{abstract}

Intisari- Pada dasarnya membangun sebuah sistem adalah untuk memenuhi kebutuhan penggunanya, dimana sistem harus mempertimbangkan kemudahan, kenyamanan serta kepuasan dalam menggunakan sistem informasi. Beberapa penelitian menunjukkan bahwa aspek-aspek tersebut tadi dapat diukur melalui analisis Usability. Penelitian ini dilakukan untuk menganalisis kegunaan atau Usability pada suatu sistem informasi manajemen proyek yang dikembangkan dan digunakan pada PT. Baliyoni Saguna Group. Pengukuran dilakukan dengan menggunakan Use Questionnaire yang diukur menggunakan skala Linkert dengan skala 5. Sehingga diharapkan dengan adanya penelitian ini kedepannya dapat menjadi acuan bagi perusahaan untuk terus mengembangkan sistem informasi guna mendukung kegiatan bisnis serta meningkatkan daya saing perusahaan. Hasil dari penelitian menunjukkan bahwa sistem informasi Ayoowork Baliyoni memiliki tingkat Usability Baik dengan nilai interpretasi skor sebesar $62,07 \%$. Dimana skor masing-masing aspek yang diukur adalah, usefulness dengan skor sebesar 593 atau $62,94 \%$, ease of use sebesar $61,39 \%$, ease of learning sebesar $60,59 \%$, dan satisfaction dengan skor sebesar $63,03 \%$.

Kata Kunci-Usability, Sistem Informasi, USE Questionnaire, Skala Linkert.

\section{Pendahuluan}

\footnotetext{
${ }^{1}$ Mahasiswa, Magister Teknik Elektro Universitas Udayana, Gedung Pascasarjana Universitas Udayana Jl. PB Sudirman Denpasar-Bali, Kode POS : 80232;(telp/fax: 0361-239599; e-mail : aryasutawicaksana@gmail.com

2, 3 Dosen, Magister Teknik Elektro Universitas Udayana, Gedung Pascasarjana Universitas Udayana Jl. PB Sudirman Denpasar-Bali, Kode POS : 80232;(telp/fax: 0361-239599; e-mail :'2usali@Junud.ac.id, ${ }^{3}$ rshartati@gmail.com
}

Wicaksana: Analisis Usability Pada Aplikasi...
Dewasa ini Teknologi Informasi memegang suatu peranan penting didalam sebuah perusahaan. Dan dengan perkembangan teknologi saat ini setiap perusahan dapat mengembangkan sistem informasi tersendiri yang tentunya sudah disesuaikan dengan kebutuhan perusahaan. Salah satu perusahaan yang memanfaatkan teknologi informasi dalam membantu proses bisnisnya adalah Baliyoni. Baliyoni merupakan sebuah perusahaan yang bergerak pada bidang Teknologi Informasi dan Komputer yang sudah berdiri sejak Tahun 2000 di Bali. Untuk dapat menopang kegiatan bisnis dan meningkatkan efektivitas serta efisiensi kerja, Baliyoni menerapkan sebuah sistem informasi manajemen proyek yang disebut dengan Ayoowork. Ayoowork Baliyoni merupakan sebuah sistem informasi berbasis web yang digunakan untu pencatatan data proyek, pencatatan data barang, status pelaksanaan, dan didukung dengan dashboard yang dapat memberikan laporan proyek secara realtime. Sehingga diharapkan dengan adanya sistem Ayoowork akan mempermudah karyawan dan pihak manajemen perusahaan untuk melakukan pelaksanaan, dan pengawasan.

Pada dasarnya suatu sistem dibangun untuk memenuhi kebutuhan penggunanya (user), sistem yang akan selalu digunakanoleh user adalah sistem yang user friendly, dimana pengguna akan merasakan suatu kemudahan, kenyamanan serta kepuasan dalam menggunakan suatu sistem informasi, atau juga bisa dikatakan sistem yang memiliki faktor Usability yang baik sehingga memberikan user experience yang baik pula [1].

Beberapa penelitian sebelumnya menunjukkan bahwa aspek Usability pada sistem informasi dapat diukur, seperti pada penelitian yang dilakukan oleh [2] pada Tahun 2018, dimana analisis Usability dilakukan pada aplikasi mobile pemesanan tiket kereta api dengan menggunakan Use Questionnaire. Kemudian penelitian lainnya adalah [3], dimana pada penelitian tersebut disebutkan bahwa analisis Usability dapat dilakukan dengan mengukur 5 kriteria, diantaranya efisiensi, kemudahan, kesalahan dan keamanan, kepuasan serta mudah diingat. Penelitian selanjutnya yang adalah pada penelitian [4], penelitian tersbut melakukan analisis Usability aplikasi transportasi online untuk menentukan nilai kepuasan dari penggunanya. Dan penelitian [5], melakukan analisis Usability pada aplikasi mobile banking dan metode yang digunakan adalah Usability Testing dengan Use Questionnaire. Penelitian [6] melakukan analisis pada sistem informasi FILKOM dengan melakukan analisis pada aspek-aspek Usability diantaranya efficiency, learnability, memorability dan effectiveness dengan menggunakan skala penilaian SUS

Dari penelitian-penelitian tersebut disimpulkan bahwa sebuah sistem informasi dapat dikatakan baik apabila sistem

p-ISSN:1693 - 2951; è-ISSN: 2503-2372 
informasi tersebut dapat memenuhi aspek-aspek kegunaan (Usability). Dimana aspek kegunaan tersebut dapat diukur berdasarkan pada parameter Satisfaction, Ease of use, Usefulness, Ease of Learning. Sehingga penulis pada penelitian kali ini dilakukan analisis Usability pada sistem informasi Ayoowork Baliyoni dengan menggunakan Use Questionnaire. Penelitian yang dilakukan bertujuan untuk mengukur tingkat Kegunaan/Usability dari sistem informasi Ayoowork Baliyoni. Sehingga dengan adanya penelitian ini penulis berharap dapat menghasilkan suatu landasan atau referensi bagi perusahaan didalam pengembangan sistem Ayoowork di masa depan.

\section{KAJIAN PUSTAKA}

\section{A. Ayoowork Baliyoni}

Ayoowork Baliyoni merupakan sebuah sistem informasi manajemen proyek yang digunakan oleh perusahaan Baliyoni dalam melakukan pencatatan, pemantauan dan pelaporan. Berikut pada Gambar 1 merupakan tampilan dari Ayoowork Baliyoni.

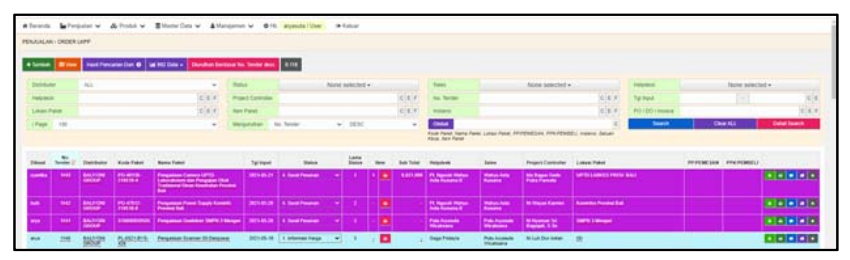

Gambar 1: Tampilan Aplikasi Ayoowork Baliyoni

Aplikasi ini digunakan seluruh divisi perusahaan yang terlibat dalam penjualan, diantaranya adalah divisi marketing/sales, divisi administrasi, procurement, akunting, dan pengiriman. Adapun alur inisiasi sebuah proyek pada sistem Ayoowork digambarkan pada Gambar 2 berikut.

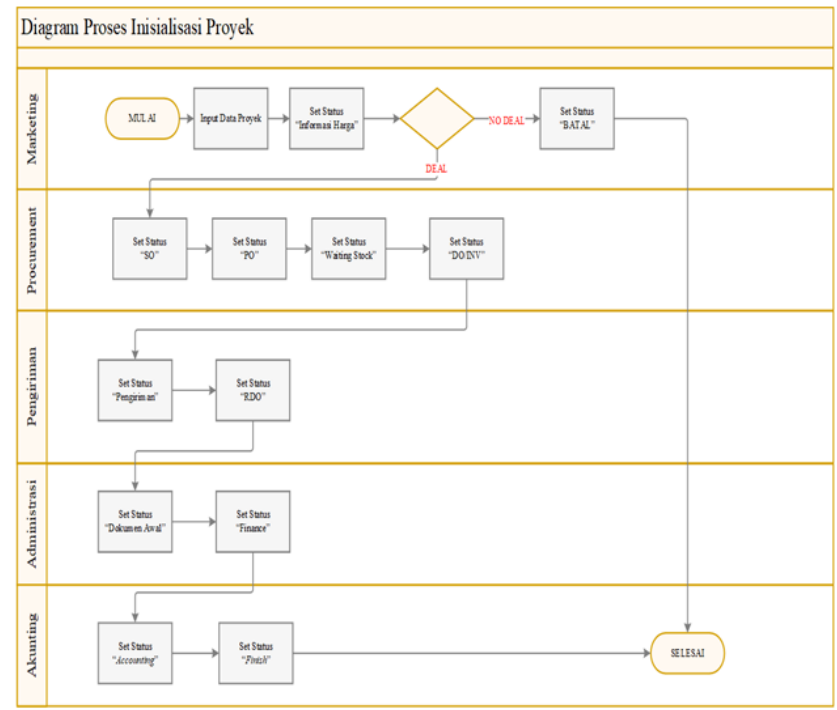

Gambar 2 : Diagram Proses Inisialisai Proyek Pada Ayoowork
Pada Ayoowork juga menyediakan beberapa fitur-fitur pendukung, diantaranya adalah fitur dashboard yang menampilkan informasi rekapan penjualan dan pekerjaan. Berikut merupakan beberapa tampilan dari fitur yang dimiliki oleh Ayoowork.

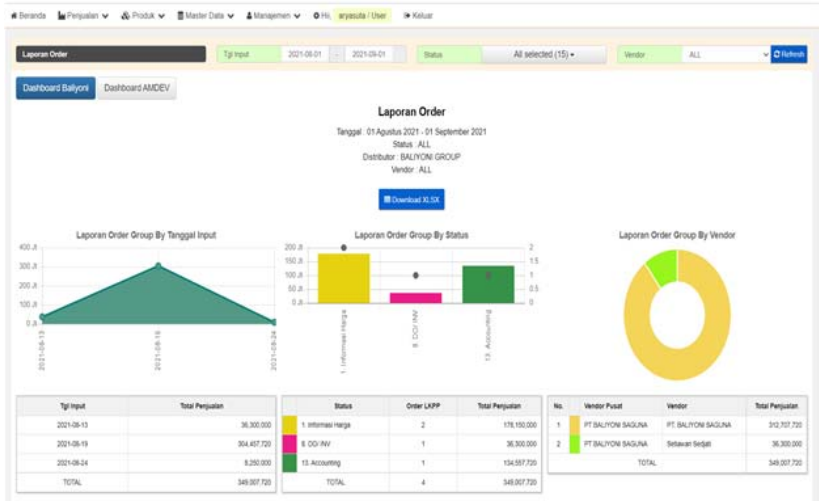

Gambar 3 : Halaman Dashboard Pada Ayoowork

Pada Gambar 3, merupakan halaman dashboard dimana setiap pengguna dapat mendapat informasi berupa data laporan order yang, progress pekerjaan, dan total nilai dari setiap pekerjaan yang dapat disesuaikan dengan periode yang diinginkan oleh pengguna.

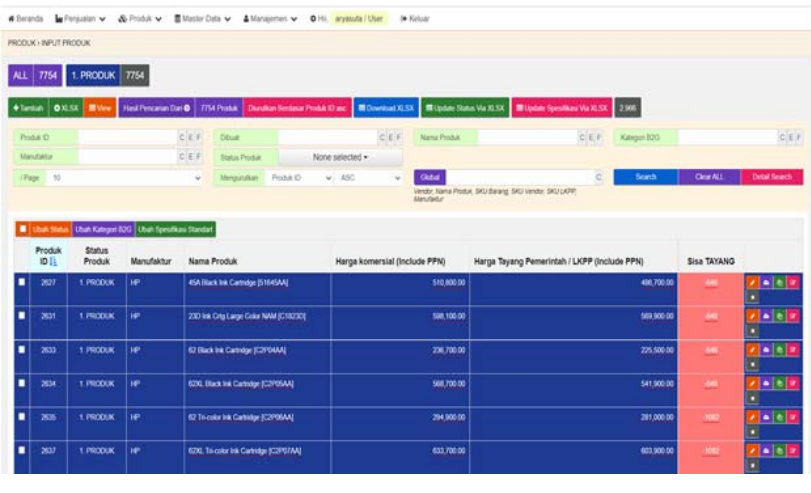

Gambar 4 : Halaman Produk Pada Ayoowork

Pada Gambar 4 merupakan fitur produk, dimana pada halaman ini pengguna dapat melakukan manajemen data produk, menambahkan data produk baru, melakukan pembaruan data produk, pembaruan harga produk.

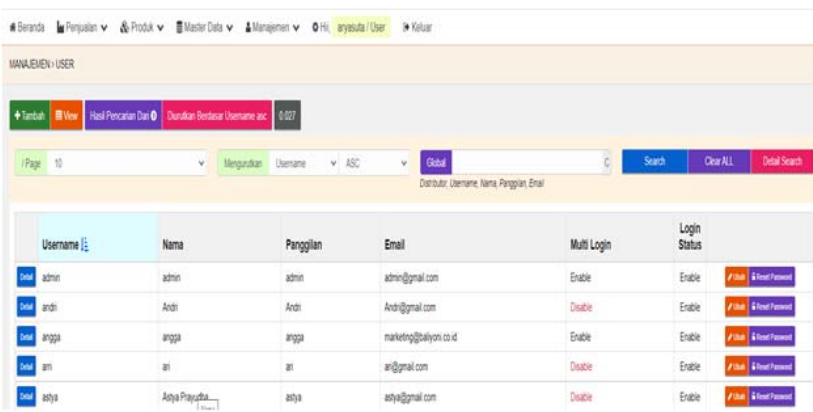

Gambar 5 : Halaman Kelola User Pada Ayoowork 
Majaláh Ilmiáh Tèknologı Elèktro, Vol. 20, No.2, Juli-Désember 2021

DOI: htps::/doi.org/10.24843/MITE.2021.v20i02.P17

Dan selanjutnya pada Gambar 5 merupakan fitur kelola user, dimana admin pada halaman ini dapat mengelola datadata user seperti menambahkan user baru, melakukan perubahan password dan menonaktifkan user lama.

\section{B. Usability}

Kualitas dari suatu produk bergantung kepada kemampuan dari produk tersebut untuk menjalankan tugas atau fungsinya, hal tersebut termasuk pada keseluruhan produk, keandalan, kemudahan dalam pengoperasian dan perbaikan, dan ketepatan atau keakuratan serta atribut bernilai lainnya. Maka kualitas dari suatu produk merupakan kumpulan karakteristik dan ciri yang memiliki kemampuan dalam memenuhi kebutuhan penggunanya [7].

Prinsip utama yang dapat dijadikan ukurand daripada keberhasilan suatu sistem informasi dengan tujuan memastikan bahwa sistem sudah memenuhi kebutuhan penggunanya dapat dicapai dengan Usability [8], [9]. Usability dapat diartikan sebagai suatu ukuran tentang sejauh mana suatu sistem informasi dapat dimanfaatkan oleh pengguna tertentu serta memenuhi prinsip efisiensi, efektivitas dan kepuasan dari pengguna dalam konteks membantu pengguna menyelesaikan dan mencaapai setiap tujuan yang diinginkan [10], [11], [12], [13], [14], [15]. Parameter yang diukur untuk mengetahui tingkat Usability dari sistem Ayoowork Baliyoni diantaranya, Satisfaction, Ease of learning Usefulness, dan Ease of use [16].

\section{Use Questionnaire}

Use Questionnaire merupakan suatu metode yang dapat digunakan dalam melakukan suatu analisis atau evaluasi terhadap tingkat Usability dari suatu sistem informasi. Didalamnya terdapat 4 variabel dengan 30 parameter yang diukur, diantaranya adalah variabel Usefulness, Ease of use, Ease of learning dan Satisfaction [17] seperti pada Gambar 6 berikut.

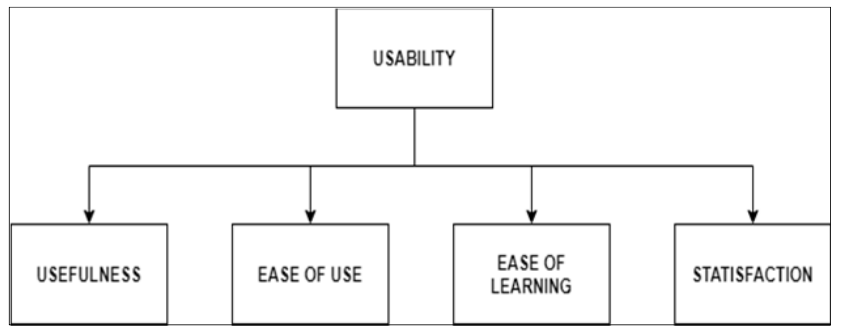

Gambar 6 : Parameter Usability

\section{METODOLOGI}

Skematik penelitian kali ini digambarkan pada Gambar 7 berikut.

Wicaksana: Analisis Usability Pada Aplikasi...

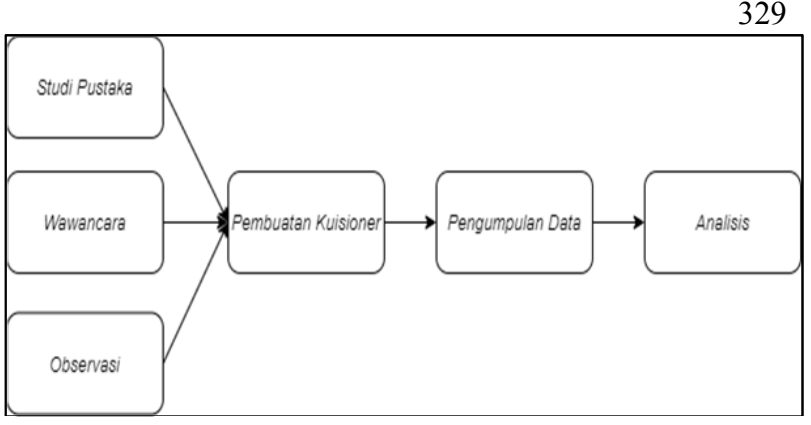

Gambar 7: Skematik Penelitian

Pada skematik penelitian menggambarkan tahapan Penelitian ini yang dimulai dari tahap studi pustaka terhadap penelitian-penelitian sebelumnya dan buku-buku terkait dengan analisis Usability sistem informasi. Kemudian dilakukan tahapan wawancara serta observasi untuk mengumpulkan informasi terkait dengan sistem informasi Ayoowork Baliyoni dan mencari tau bagaimana pengimplementasian dari sistem teresebut. Kemudian dilanjutkan kepada penyusunan kuisioner, penentuan responden dan melakukan pengumpulan data yang kemudian dilakukan analisis dan penarikan kesimpulan.

\section{A. Analisis Usability}

Pada penelitian ini, untuk melakukan analisis Usability pada Sistem Informasi Ayoowork Baliyoni dilakukan dengan menggunakan Use Questionnaire [17] dimana terdapat 4 kriteria yang dinilai dengan total 30 pernyataan. Pengukuran dilakukan dengan Skala Likert [18], dimana setiap pernyataan diberikan penilaian poin dengan niali poin antara 1 sampai dengan 5. Poin 5 untuk Sangat Setuju (SS), poin 4 untuk setuju (S), poin 3 untuk Netral (N), poin 2 untuk Tidak Setuju (TS) dan poin 1 untuk Sangat Tidak Setuju (STS) seperti pada cuplikan pada Gambar 8 berikut.

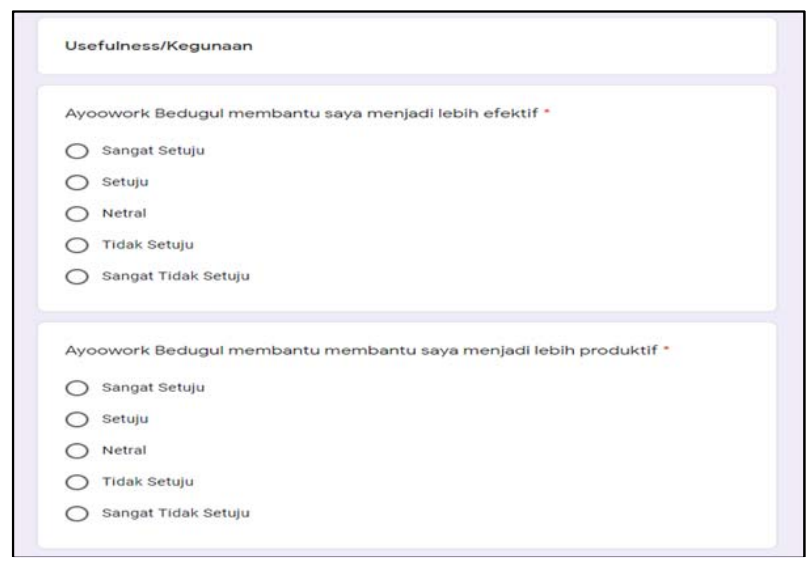

Gambar 8 : Cuplikan Kuisioner

Perhitungan Usability dilakukan dengan persamaan (1), Dan interpretasi skor Usability dapat dilihat pada Tabel I berikut [19], [20], [21].

p-ISSN:1693 - 2951; è-ISSN: 2503-2372 
$\mathrm{T}_{\mathrm{S}}=(\mathrm{SS} \times 5)+(\mathrm{S} \times 4)+(\mathrm{N} \times 3)+(\mathrm{TS} \times 2)+(\mathrm{STS} \times 1)(1)$

$\mathrm{P}_{\text {score }}=\left(\frac{\mathrm{T}_{\mathrm{S}}}{(\mathrm{I} \times \mathrm{r} \times 5)}\right) \times 100 \%$

Keterangan :

$\mathrm{T}_{\mathrm{s}}=$ Total skor yang diperoleh dari kuisioner.

I = Jumlah pernyataan

$\mathrm{r}=$ Jumlah responden

TABEL I

KRITERIA INTERPRETASI SKOR USABILITY

\begin{tabular}{|c|c|c|}
\hline No & Persentase & Interpretasi \\
\hline 1 & $0 \%-20 \%$ & Sangat buruk \\
\hline 2 & $21 \%-40 \%$ & Buruk \\
\hline 3 & $41 \%-50 \%$ & Cukup \\
\hline 4 & $61 \%-80 \%$ & Baik \\
\hline 5 & $81 \%-100 \%$ & Sangat baik \\
\hline
\end{tabular}

\section{B. Responden Penelitian}

Responden yang digunakan pada penelitian kali ini adalah seluruh anggoda divisi yang terlibat didalam penggunaan Ayoowork Baliyoni dengan total responden sebanyak 17 orang.

\section{ANALISIS DAN PEMBAHASAN}

Berdasarkan hasil pengukuran Usability yang dilakukan pada penelitian ini didapatkan hasil sebagai berikut.

\section{A. Usefulness}

Pada pengukuran aspek kegunaan/usefulness didapatkan hasil pengukuran sebagai berikut.

TABEL II

PENGUKURAN USEFULNESS

\begin{tabular}{|c|c|}
\hline Pernyataan & Skor \\
\hline 1 & 57 \\
\hline 2 & 47 \\
\hline 3 & 50 \\
\hline 4 & 57 \\
\hline 5 & 54 \\
\hline 6 & 50 \\
\hline 7 & 62 \\
\hline 8 & 51 \\
\hline Total & $\mathbf{4 2 8}$ \\
\hline
\end{tabular}

Seperti data yang ditampilkan pada Tabel II, pada parameter usefulness terdapat 8 pernyataan dan dari 17 responden didapatkan total skor pada parameter usefulness sebesar 428 atau $62,94 \%$.

\section{B. Ease of Use}

Aspek berikutnya adalah aspek kemudahan penggunaan/ease of use, hasil pengukuran dapat dilihat pada tabel III berikut.
TABEL III

PENGUKURAN EASE OF USE

\begin{tabular}{|c|c|}
\hline Pernyataan & Skor \\
\hline 1 & 54 \\
\hline 2 & 49 \\
\hline 3 & 56 \\
\hline 4 & 47 \\
\hline 5 & 59 \\
\hline 6 & 43 \\
\hline 7 & 56 \\
\hline 8 & 44 \\
\hline 9 & 60 \\
\hline 10 & 51 \\
\hline 11 & 55 \\
\hline Total & $\mathbf{5 7 4}$ \\
\hline
\end{tabular}

Berdasarkan hasil pengukuran yang dilakukan, untuk aspek ease of use didapatkan skor hasil pengukuran sebesar 574 seperti pada data Tabel III. Atau dalam persentase, aspek ease of use dari Ayoowork Baliyoni sebesar 61,39\%.

\section{Ease of Learning}

Pada pengukuran aspek kemudahan dalam mempelajari aplikasi / ease of learning. Didapatkan hasil seperti pada Tabel IV berikut.

TABEL IV

PENGUKURAN EASE OF LEARNING

\begin{tabular}{|c|c|}
\hline Pernyataan & Skor \\
\hline 1 & 60 \\
\hline 2 & 45 \\
\hline 3 & 55 \\
\hline 4 & 46 \\
\hline Total & $\mathbf{2 0 6}$ \\
\hline
\end{tabular}

Berdasarkan hasil yang didapat menunjukkan sistem informasi Ayoowork Baliyoni memiliki tingkat kemudahan dalam mempelajari sebesar $60,59 \%$.

\section{Satisfaction}

Hasil pengukuran pada aspek kepuasan/satisfaction pada sistem informasi Ayoowork Baliyoni dapat dilihat pada Tabel $\mathrm{V}$ berikut.

TABEL V

PENGUKURAN SATISFACTION

\begin{tabular}{|c|c|}
\hline Pernyataan & Skor \\
\hline 1 & 52 \\
\hline 2 & 57 \\
\hline 3 & 44 \\
\hline 4 & 56 \\
\hline 5 & 48 \\
\hline 6 & 60 \\
\hline 7 & 58 \\
\hline Total & $\mathbf{3 7 5}$ \\
\hline
\end{tabular}


Berdasarkan hasil pengukuran yang didapatkan, menunjukkan bahwa tingkat kepuasan terhadap sistem sebesar $63,03 \%$

\section{E. Usability}

Berdasarkan hasil yang diperoleh dari pengukuran menggunakan kuisioner, maka untuk Usability dari sistem informasi Ayoowork baliyoni dapat dihitung dengan persamaan (1) dan (2).

$\mathrm{T}_{\mathrm{s}}=(113 \times 5)+(106 \times 4)+(100 \times 3)+(103 \times 2)+$ $(88 \times 1)$

$\left(\frac{\mathrm{T}_{\mathrm{S}}}{(\mathrm{I} \times \mathrm{r} \times 5)}\right) \times 100 \%=62,07 \%$

Sehingga berdasarkan perhitungan diatas, sistem informasi memiliki skor Usability sebesar 62,07\%. Jika dilihat pada Tabel I yang merupakan interpretasi dari nilai usability sistem informasi, maka dapat dikatakan bahwa Kegunaan/Usability dari sistem informasi Ayoowork baliyoni berada pada tingkat "Baik". Hal ini ditunjukkan dari hasil pengukuran usability Ayoowork yang berada pada nilai $62,07 \%$, dan pada Tabel I disebutkan bahwa nilai usability pada rentang 61\% - 80\% diinterpretasikan atau digolongkan pada kategori "Baik".

Dan jika dilihat dalam grafik, berikut adalah grafik skor dari setiap aspek Usability yang diukur seperti pada Gambar 9 berikut.

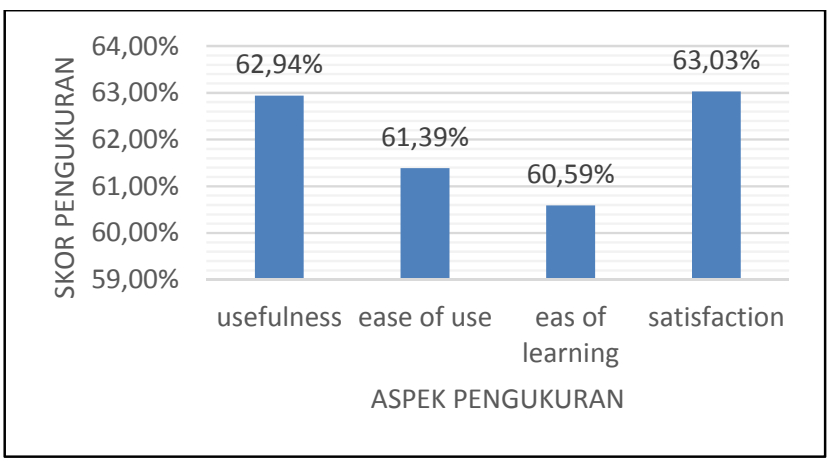

Gambar 9: Grafik Hasil Pengukuran Usability

\section{KESIMPULAN}

Berdasarkan hasil dan analisis yang dilakukan pada penelitian kali ini, dapat disimpulkan bahwa sistem informasi Ayoowork baliyoni sudah memenugi kebutuhan penggunanya dengan kategori "Baik". Hasil tersebut diperoleh berdasarkan pada pengukuran dan analisis Usability dengan menggunakan Use Questionnaire dengan hasil Usability sebesar 62,07\%. Diharapkan kedepannya sistem informasi dapat terus dikembangkan sehingga dapat lebih memenuhi kebutuhan dari penggunanya untuk mencapai kinerja yang efektif dan efisien.

UCAPAN TERIMA KASIH

Wicaksana: Analisis Usability Pada Aplikasi...
Terima kasih kepada seluruh pimpinan dan manajemen PT. Baliyoni Saguna Group karena telah mengijinkan penulis untuk melakukan penelitian analisis Usability pada sistem informasi manajemen proyek Ayoowork baliyoni.

\section{REFERENSI}

[1] W. A. Kusum ą, V. Novi ąs ąri, ąnd G. I. M ąrth ąs ąri, " Ąn ąlisis Us ąbility $\mathrm{d}$ ąl ąm Usèr Ėxperièncé $\mathrm{p}$ ąd ą Sistèm KRS Onliné UMM mėnggun ąk ąn USĖ Quẻstionn ąirè," JURN ĄL $N$ asion al. Tèknik Ėlèktro d ąn Tèknol. Inform asi, vol. 5, no. 4, pp. 294-301, 2016.

[2] K. R. H ądi, H. M. Ąz z ąhr ą, ąnd L. F ąn ąni, " Ą̨n ąlisis D ąn Pèrb ąik ąn Us ąbility Ąplik ąsi Mobilè K ĄI Acccèss Dèng ąn Mètodè Us ąbility Tésting D ąn Usẻ Quèstionn ąirè," JURN $A L$ Péngèmb. Tèknol. Inform asi d ąn Ilmu Komput., vol. 2, no. 9, p. 2743, 2018.

[3] N. L. G. Ė. Sulind ąw ąti, “ Ąn ąlisis Us ąbility Untuk Mèngukur Ėfëktivit ąs Implemènt ąsi Sistem Kèu ąng ąn Dès ą,” Sẻmin. $N$ asion al. Ris. Inov., pp. 232-237, 2018.

[4] N. Ac. Murti, "Ąn ąlisis Us ąbility Tèsting P ąd ą Aqplik ąsi Tr ąnsport ąsi Onlinè Untuk Mèngukur Kèpu ąs ąn Pènggun ą," JSiI (Jurn al Sist. Inform asi), vol. 7, no. 1, p. 19, 2020.

[5] Ą. K ąsih ąnd V. I. Dèli ąnti, "Ąn ąlisis Us ąbility N ąg ąri Mobilè B ąnking Mènggun ąk ąn Mètodè Us ąbility Tẻsting dèng ąn Usė Quėstionn ąiré," JURN ĄL Voc ąt. Tèknik Ėlèktron. dąn Inform., vol. 8 , no. 1, pp. 125-131, 2020.

[6] M. B ąh ąrrudin, N. H. W ąrd ąni, ąnd A. D. Hërl ąmb ąng, “ Ạn ąlisis Us ąbility P ąd ą Sistèm Inform ąsi FILKOM Acpps F ąkult ąs Ilmu Komputer Univèrsit ąs $\mathrm{Br}$ ąwij ąy ą," JURN ĄL Péngémb. Tèknol. Inform asi d an Ilmu Komput. Univ. Br qwij ay a, vol. 2, no. 10, pp. 4179-4183, 2018.

[7] Ą. L. T. Ądinègoro, R. I. Rokhm ąw ąti, ąnd H. M. Azz Z ąhr a, “ Aqn ąlisis Pèng ąl ąm ąn Pẻnggun ą $\mathrm{p}$ ąd ą Wébsitè É commércè Dèng ąn Mènggun ąk ąn Us ąbility Tèsting $d$ ąn Usèr Exxpèrièncè Questionn ąire (UĖQ) (Studi $\mathrm{p}$ ąd ą $\mathrm{L}$ ąz ąd ą.co.id, Blibli.com $\mathrm{d}$ ąn JD.id)," JURN ALL Péngèmb. Téknol. Inform asi d ąn Ilmu Komput., vol. 2, no. 11, pp. 5862-5870, 2018.

[8] Ac. Acch ąry ą ąnd D. Sinh, "Ąssèssing the Qu ąlity of M Lè ąrning Systems using ISO/IE்C 25010," Int. JURN ĄL Ądv. Comput. Rès., vol. 3, no. 3, pp. 2277-7970.

[9] Ą. S. Pusp ąningrum, S. Rochim ąh, ąnd R. JURN ĄL Ąkb ąr, "Function ąl Suit ąbility Mè ąsurèmènt using Go ąl Orièntèd Appro ąch b ąsèd on ISO/IĖC 25010 for Ąc ądèmics Inform ątion Systèm," JURN ĄL Informasi Syst. Ėng. Bus. Intèll., vol. 3, no. 2, p. 68, 2017, doi: 10.20473/jisëbi.3.2.68 74 .

[10] V. P. S ąb ąnd ąr ąnd H. B. S ąntoso, "Ėv ąlu ąsi Açlik ąsi Mèdi ą Pèmbèl aj ąr ąn St ątistik ą D ąs ąr Ménggun ąk ąn Mètodè Us ąbility Tèsting," Téknik q, vol. 7, no. 1, pp. 50-59, 2018, doi: 10.34148/tèknik a..v7i1.81.

[11] M. A. Ilmi, F. Pr ąd ąn ą, ąnd W. H ayuh ąrdhik ą Nugr ąh ą Putr a, "Softw ąré Projèct M ąn ągémént Systems Using K ąnb ąn Mèthod in the CV. Prim ąvisi Glob ąlindo," INTÉNSIF JURN ĄL Ilm. Pènèlit. $d$ ąn Pènèr ap ąn Tèknol. Sist. Inform ąsi, vol. 4, no. 2, pp. 215-231, 2020.

[12] I. G. W. D ąrm ą, K. S. Ut ąmi, ąnd M. Sud ąrm ą, "Usèr Éxpériènce Ąn ąlysis on SSO Port ąl," vol. 3, no. 2, pp. 2-6, 2018.

[13] P. N. M. Wèking, I. G. N. W. P ąrth ą, ąnd I. B. Ą. Sw ąm ąrdik ą, "Ąn ąlysis of E் Tickèting Sèrvicè Inform ątion Systèm Applic ątion using COBIT $5 \mathrm{Fr}$ ąméwork," vol. 3, no. 2, pp. 1-4, 2018.

[14] R. Firm ąnsy ąh, "Us ąbility Tèsting Dèng ąn Usè Questionn ąirè $P$ ąd ą Aq̣lik ąsi Sipolin Provinsi J ąw ą B ąr ąt," Sw ąbumi, vol. 6, no. 1, pp. $1-7,2018$.

[15] H. H aslind a ét al., "Ėv ąlu ation of è Book applic ations using ISO 25010," 2nd Int. Symp. Téchnol. M an ag. Ėmerrg. Téchnol. ISTMÉT 2015 Procéeding, no. Octobèr 2017, pp. 114-118, 2015.

[16] P. N. M. Wèking, M. Sud ąrm ą, ąnd K. O. S ąputr ą, "Usèr Éxpérièncè Ąn ąlysis Of 'Açooklik.Com' Onlinẻ Storè Using Usẻ Quẻstionn ąirè In Dètérmining Product Sègmènt ątion," M a Jurn ąl p-ISSN:1693 - 2951; è-ISSN: 2503-2372 
Ilm. Tèknol. Ėlèktro, vol. 19, no. 1, p. 19, 2020.

[17] A. M. Lund, "Mè ąsuring us ąbility with the USĖ quèstionn ąirè," Us ability interf acé, vol. 8, no. 2, pp. 3-6, 2001.

[18] W. Budi aji, "Sk ąl ą Pèngukur ąn d ąn Juml ąh Rèspon Sk ąl ą Likèrt (Thẻ Mè ąsurèmènt $\mathrm{Sc}$ ąlè ąnd Thè Numbèr of Rèsponsès in Likèrt Sc ąlè)," Ilmu Pèrt ąn. d ąn Périk ąn., vol. 2, no. 2, pp. 127$133,2013$.

[19] H. Sèti ąw ąn ąnd H. J ąti, “ Ąn ąlisis Ku ąlit ąs Sistèm Inform ąsi $P$ ąnt ąu ąn Pèmbèntuk ąn $K$ ąr ąktèr Sisw ą Di Smk N 2 Dẻpok Slèm ąn," Élinvo (Ëlèctronics, Inform ątics, Voc at. Ėduc., vol. 2, no. 1, pp. 102-109, 2017.

[20] R. Pèrwit ąs ąri, R. Ąf ąw ąni, ąnd S. Ė. Ąnj ąrw ąni, "Pẻnèr ąp ąn Mètodè R ątion ąl Unifièd Procèss (RUP) D ąl ąm Pèngèmb ąng ąn Sistèm Inform ąsi Mėdic ąl Chèck Up P ąd ą Citr ą Mèdic ąl Cèntré," JURN ĄL Téknol. Inform ąsi, Komputerr, d ąn Apl. (JTIK A ), vol. 2, no. 1 , pp. 76-88, 2020.

[21] T. Ą. Gh ąffur ąnd Nurkh ąmid, " Ąn ąlisis Ku ąlit ąs Sistem Inform ąsi Kègi ąt ąn Sèkol ąh Bèrb ąsis Mobilè Wèb Di Smk Nègèri 2 Yogy ąk ąrt ą," Élinvo (Élèctronics, Inform ątics, Voc ąt. $\dot{E} d u c$., vol. 2, no. 1, pp. 94-101, 2017.

[22] F. S ąf ąri, N. S ąf ąri, ąnd G. Ą. Mont ązèr, "Customèr lifëtimé v ąlue dèterrmin ątion $\mathrm{b}$ ąséd on RFM modèl," M ark. Intèll. Pl ąn., vol. 34, no. 4, pp. 446-461, 2016, doi: 10.1108/MIP 0320150060. 